\title{
АНАЛИЗ СТРУКТУРЫ ОНКОЛОГИЧЕСКОЙ ПАТОЛОГИИ СРЕДИ ЖЕНСКОГО НАСЕЛЕНИЯ Г. МОСКВЫ
}

\section{ANALYSIS OF THE STRUCTURE OF ONCOLOGICAL PATHOLOGY AMONG THE WOMEN POPULATION OF MOSCOW \\ N. Stasevich \\ L. Polonskaya \\ M. Gadzhieva}

Summary. In recent years, there has been a significant increase in the number of patients and invalids due to malignant neoplasms. The problem of cancer among the female population is the most important problem in social medicine, not only in Russia, but also abroad.

Malignant neoplasms are also a medical and social problem due to the high morbidity and mortality of the female population. Thus, more women die from ovarian cancer every year than from cervical and endometrial cancer combined.

Purpose of the study: to analyze the most common forms of cancer incidence among the female population of Moscow and to propose approaches for their early detection.

Keywords: breast cancer, cancer of the female genital organs, medicosocial significance, measures for early detection.

\section{Введение}

D ак - это общее название большой группы заболеваний, которые могут поражать любые ткани тела. Характерным признаком рака является быстрое образование и рост аномальных клеток, способных распространяться в другие органы. По данным ВОЗ в 2008 году от рака умерло 7,6 миллиона человек, что соответствует $13 \%$ от числа всех смертей в мире. Со-
Стасевич Наталья Юрьевна

Д.м.н., ФГБНУ «Национальный НИИ общественного здоровья имени Н.A. Семашко»

n.stasevich@outlook.com

Полонская Люсине Суреновна

К.м.н., ФГБНУ «Национальный НИИ общественного здоровья имени Н.A. Семашко»

m17951447@gmail.com

Гаджиева Мадина Шахапасовна

ФГБНУ «Национальный Научно-исследовательский институт общественного здоровья имени

Н.A. Семашко»

shaxapasovna1@mail.ru

Аннотация. В последние годы отмечен значительный рост количества больных и инвалидов вследствие злокачественных новообразований. Проблема онкологических заболеваний среди женского населения является наиважнейшей проблемой в социальной медицине не только в России, но и за рубежом.

Злокачественные новообразования представляют медико-социальную проблему также в связи с высокой заболеваемостью и смертностью женского населения. Так от рака яичников ежегодно умирают больше женщин, чем от рака шейки матки и рака эндометрия вместе взятых.

Цель исследования: проанализировать наиболее распространённые формы онкологической заболеваемости среди женского населения г. Москвы и предложить подходы их раннего выявления.

Ключевые слова: рак молочной железы, рак женских половых органов, медико-социальная значимость, мероприятия по раннему выявлению.

отношение числа заболевших к умершим составляет 1 к 0,6. Несмотря на то, что 2017 год объявлен ВОЗ ориентировочным годом победы над раком, заболеваемость данной патологией остаётся на высоком уровне $[1,2,3]$.

Понятно, что на сегодняшний день основную угрозу здоровью и жизни человека представляют сердечно-сосудистые, а не онкологические заболевания. Например, в нашей стране злокачественные новообра- 
зования остаются второй основной причиной смерти населения, но они значительно уступают смертности при болезнях системы кровообращения.

Российские женщины чаще мужчин болеют раком (53,3\% и 46,5\%), но мужчины умирают почти в 2 раза чаще.

Средний возраст выявления заболевания у женщин составляет 62,9 года, у мужчин - 63,3 года. Средний возраст умерших для женщин составляет 67,0 лет, у мужчин - 64,9 года.

Наиболее часто встречаемые типы рака среди мужчин и женщин отличаются друг от друга. На протяжении нескольких лет у мужчин первые места занимают опухоли бронхов и лёгкого (21,9\%) и желудка $(12,0 \%)$; у женщин - рак молочной железы (19,9\%), затем желудка и кожи $[4,5]$.

Около трети случаев смерти мужчин обусловлены раком лёгкого. Опухоли желудка являются причиной смерти ещё 13,3\% мужчин. У женщин к смерти чаще всего приводят злокачественные новообразования молочной железы (17,3\%). Далее в порядке следуют новообразования желудка (11,7\%), ободочной кишки (9,5\%), лёгкого и прямой кишки (по 6,4\%), яичников $(5,7 \%)$, лимфатической и кроветворной ткани $(5,4 \%)$, тела $(4,8 \%)$ и шейки $(4,6 \%)$ матки [6].

Таким образом, онкологические заболевания остаются в числе приоритетов здравоохранения в связи с постарением населения и неудовлетворительными результатами профилактики и лечения.

\section{Шель исслеАования}

Проанализировать наиболее распространённые формы онкологической заболеваемости среди женского населения г. Москвы и предложить подходы их раннего выявления.

\section{Материалы и метолы}

В исследовании использовались данные официальной статистики, выложенные в электронных ресурсах: https://rosstat.gov.ru/ и http://rosstatistika.ru/. В исследовании также были проанализированы данные учётной документации 9 женских консультаций г. Москвы, а конкретно формы статистического учёта по диспансерным группам наблюдения по онкопатологии: формы n 030/y-04 «Контрольная карта диспансерного наблюдения», а также формам учётности, согласно Приказу Минздрава России от 15 ноября 2012 года N915н «Об утверждении Порядка оказания медицинской помощи населению по профилю «онкология» (с изменениями на 5 февраля 2019 года), в котором в п. 24 сказано «В случае подтверждения у больного факта наличия онкологического заболевания, информация об уточненном диагнозе больного направляется из организационно-методического отдела онкологического диспансера в центр амбулаторной онкологической помощи либо первичный онкологический кабинет, первичное онкологическое отделение медицинской организации, оказывающей медицинскую помощь больным с онкологическими заболеваниями, для последующего диспансерного наблюдения больного. (Пункт в редакции, введенной в действие с 1 мая 2019 года приказом Минздрава России от 5 февраля 2019 года N48н.».

Всего было обследовано 1089 женщин, состоящих на учёте по поводу рака женских половых органов и рака молочной железы за 2019 г.- 8 месяцев 2020 года.

\section{Результаты}

Как показал анализ официальных данных, в 2019 г. в Российской Федерации впервые в жизни выявлено 624709 случаев злокачественных новообразований (в том числе 285949 и 338760 у пациентов мужского и женского пола соответственно). Прирост данного показателя по сравнению с 2017 г. составил 1,2\%. На конец 2018 г. в территориальных онкологических учреждениях России состояли на учете 3762218 пациентов (2017 г.- 3630567).

Совокупный показатель распространенности составил 2562,3 на 100000 населения. Диагноз злокачественного новообразования был подтвержден морфологически в 93,0\% случаев (2008 г.- 83,2\%), наиболее низкий удельный вес морфологической верификации диагноза наблюдается при опухолях поджелудочной железы (65,8\%), печени (68,9\%), трахеи, бронхов, легкого $(79,9 \%)$, почки $(85,5 \%)$, костей и суставных хрящей $(90,7 \%)$.

Распределение впервые выявленных злокачественных новообразований по стадиям в 201 году: І стадия$30,6 \%$, II - 25,8\%, III - 18,2\%, IV - 20,3\%.

Ведущими локализациями в общей (оба пола) структуре онкологической заболеваемости являются: кожа (12,6\%, с меланомой - 14,4\%), молочная железа (11,4\%), трахея, бронхи, легкое (9,9\%), ободочная кишка (6,9\%), предстательная железа (6,8\%), желудок (5,9\%), прямая кишка, ректосигмоидное соединение, анус (5,0\%), лимфатическая и кроветворная ткань (4,8\%), тело матки (4,3\%), почка (3,9\%), поджелудочная железа(3,1\%), шейка матки $(2,8 \%)$, мочевой пузырь (2,8\%), яичник (2,3\%) (таблица 1$)$. 
Таблица 1. Ранговая структура ведущих нозологических форм онкологической патологии (в \% отношении).

\begin{tabular}{|l|l|l|}
\hline Ранги & Нозологическая форма & Соотошение в $\%$ \\
\hline 1 & Меланома кожи & 14,4 \\
\hline 3 & Молочная железа & 11,4 \\
\hline 4 & Трахеи, бронхи, лёгкие & 9,9 \\
\hline 5 & Ободочная кишка & 6,9 \\
\hline 6 & Предстательная железа & 6,8 \\
\hline 7 & Желудок & 5,9 \\
\hline 8 & Прямая кишка, ректосигмоидное соединение, анус & 5,0 \\
\hline 9 & Лимфатическая и кроветворная ткань & 4,8 \\
\hline 10 & Тело матки & 4,3 \\
\hline 11 & Почка & 3,9 \\
\hline 12 & Поджелудочная железа & 3,1 \\
\hline 13 & Шейка матки & 2,8 \\
\hline 14 & Мочевой пузырь & 2,8 \\
\hline
\end{tabular}

Поскольку здоровье женского населения напрямую связано с рождением здоровой нации, то нами особое значение было уделено состоянию онкологической патологической поражённости наиболее распространёнными формами рака среди женщин.

В ходе исследования был проведен анализ онкозаболеваемости в зависимости от возраста среди трудоспособного женского населения в мегаполисе.

Установлено, что наиболее высокий показатель онкологических заболеваний в среднем за годы исследования 2019-8 месяцев 2020 гг.) отмечался в возрастной группе женского населения 25-34 года - 38,8 на 100 тыс. человек соответствующего пола. Далее в порядке убывания следует возрастная группа 3544 года - среднегодовой показатель составил 35,7 на 100 тыс. человек соответствующего возраста женского населения.

Как показывают результаты исследований, сравнительный анализ показателей онкологических заболеваний среди женщин наиболее распространёнными формами рака -органов пищеварения и дыхания с данными заболеваемости молочной железы и половых органов не отражает истиной картины эпидемиологического процесса, поскольку имеет место поздняя диагностика данных патологий. Прогностический расчет до 2025 г. показал, что заболеваемость и распространенность онкологической патологии среди трудоспособного женского населения г. Москвы будут иметь тенденцию к росту именно по раку молочной железы и женских половых органов.

Рак молочной железы занимает одно из лидирующих мест в онкопатологии женского населения трудоспособного возраста, в связи с чем данная патология изучалась более детально. Среднегодовой темп прироста данного показателя за анализируемый период на всей территории страны составил 2,58\%, г. Москве3,47\%, соответственно. Наиболее высокий уровень повозрастного показателя заболеваемости злокачественными новообразованиями молочной железы в группе 30-39 лет в среднем по стране был отмечен в 2019 году, равный 24,14 на 100 тыс. женского населения, в то время как в г. Москве в 2019 году был 31,09 на 100 тыс. женского населения.

Поскольку из числа онкопатологии, приводящей к инвалидности на первом месте стоит рак половых органов, то именно эта нозология была рассмотрена также более детально. В целом за десять лет число впервые признанных инвалидами вследствие злокачественных новообразований половых органов уменьшилось на 5,2\%, что обусловлено внедрением в практику медицинских организаций новых современных методов диагностики онкологических заболеваний, улучшением диспансеризации в Москве и Московской области и применением адекватных методов лечения в рамках Государственной программы развития здравоохранения на 2018-2025 годы, утвержденной Постановлением Правительством РФ от 26.12.2017 № 1640 
«Об утверждении государственной программы Российской Федерации «Развитие здравоохранения».».

Исследование структуры первичной инвалидности вследствие злокачественных новообразований женских половых органов в Москве с учетом возраста свидетельствовало о преобладании женщин молодого и среднего возраста (от $87,8 \%$ в 2016 г. до $90,2 \%$ в 2019 г.).

Основным звеном в системе противораковой борьбы, обеспечения квалифицированной, специализированной стационарной и поликлинической медицинской помощи населению является онкологический диспансер. В этом учреждении осуществляется организационно-методическое руководство и координирование деятельности всех онкологических учреждений, находящихся в подчинении.

Однако в онкологическом диспансере в основном решаются медицинские задачи лечения и изучения раковых опухолей. Комплекс медицинских, психологических и социальных задач призваны решать хосписы.

Обсуждение. С целью снижения выхода на инвалидность онкологических изучена медико-социальная эффективность проведения реабилитационных мероприятий в восстановительном отделении поликлиники диспансера. Обследованию подверглось 485 больных наиболее распространёнными формами рака: молочной железы и женских половых органов. Повторное освидетельствование, медико-социальной экспертной комиссии показало, что максимальная часть по истечении первого года инвалидности полностью восстановили трудоспособность при раке молочной железы $(36,5 \%)$, женских половых органов (26,7\%). До настоящего времени остаётся низкой доля лиц восстановивших трудоспособность при злокачественном заболевании шейки матки - 19,7\%.

Для расчёта стоимости одного посещения с целью получения восстановительной помощи была использована методика Ю.П. Лисицына (2010) по разделению расходов на содержание больных в стационаре и поликлинике многопрофильной больницы. Данные расчета показали, что восстановительная помощь онкологических больных в амбулаторных условиях при сохранении медико-социальной эффективности, обходится значительно дешевле (у больных раком молочной железы в 4,3 раза, у больных раком женских половых органов - в 3 раза), по сравнению с восстановительной помощью, оказанной в условиях стационара.

Нами были предложены механизмы раннего выявления онкологических заболеваний, связанные с со- вершенствованием организации работы на амбулаторно-поликлиническом этапе:

- проведение профилактических осмотров женского населения обслуживаемой территории с целью своевременного выявления онкозаболеваемости;

- формирование поликлинических групп риска развития злокачественных новообразований в зависимости от факторов риска и обеспечения полного и качественного обследования;

- использование различных методов современной диагностики онкологических заболеваний в зависимости от экономической целесообразности и медицинской эффективности их применения;

- повышение бдительности врачей медицинских организаций общей лечебной сети в отношении онкозаболеваемости женского населения, для чего постоянно проводить семинары и конференции с участием врачей онкологов.

В связи с развитием и внедрением высокотехнологичных методов лечения онкологических заболеваний, уже сегодня стало возможным радикальное лечение большинства пациентов, выполняя обширные органоуносящие оперативные вмешательства, химиотерапию и лучевую терапию, что в ближайшие годы увеличит количество инвалидизированных женщин, излеченных от рака. Однако реабилитация, с целью социальной адаптации, недостаточно развита, в связи, с чем больной после радикального лечения остается без внимания.

Необходимо отметить, что в реабилитации нуждаются не только пациенты, имеющие группу инвалидности, но и больные с I - II стадиями заболевания, прошедшие радикальное лечение, так как диагноз рак - это всегда стресс, а лечение не всегда щадящее.

Медико-социальная работа также направлена на улучшения качества жизни онкологических больных.

Следует особо подчеркнуть, что до настоящего времени не была проведена комплексная научная разработка основных категорий ограничения жизнедеятельности и социальной недостаточности пациентов с онкологическими заболеваниями и впервые признанных инвалидами. Отсутствуют данные о степени взаимосвязи нарушенного здоровья, клинического прогноза, ограничения жизнедеятельности и социальной недостаточности в этом обширном контингенте больных, что делает актуальной проблему медико-социальной экспертизы первичной инвалидности вследствие этой тяжелой онкологической патологии. 
Особую актуальность приобретает в настоящее время качество жизни больных и инвалидов после проведенного радикального и паллиативного лечения, а также потребность последних в медико-социальной помощи.

\section{ВывО $\triangle \mathrm{b}$}

1. Таким образом, решение проблемы по предупреждению распространения онкопатологии и совершенствованию онкологической помощи в крупном мегаполисе как г. Москва необходимо осуществлять путём обоснованного выбора мероприятий, приоритетными из которых должна стать предложенная нами программа амбулаторной восстановительной помощи.

2. Решение разнообразных проблем инвалидности в современном обществе основано на разработке и использовании комплексной многопрофильной реабилитации, которая обеспечивает независимую жизнедеятельность инвалидов. Особую значимость при этом приобретает изучение механизмов социальной компенсации и адаптации.

\section{ЛИТЕРАТУРА}

1. Завольская, Ж.А., Кузнецов, В.В., Лазарева, Н.И. и др. Факторы прогноза и тактика лечения больных эндометриальными стромальными саркомами матки // Сибирский онкологический журнал. 2008. № 3. С. 16-20.

2. Запущенный рак молочной железы. Здравоохранение Таджикистана, 2004 г., № 3. С. 63-65.

3. Кедрова, А.Г. Персистирующий рак яичников: активная тактика лечения // Материалы Х Российского онкологического конгресса. М., 2006. С. 64-68.

4. Ковалев, Б.Н., Старинский, В.В. Эпидемиология рака молочной железы в России (2000 г.) // Гормонозависимые опухоли (Материалы IX Всероссийской конференции онкологов). - СПб., 2002.- - С. 40-42.

5. Комаров, И.Г. Метастазы злокачественных опухолей без выявленного первичного очага / И.Г. Комаров, Д.В. Комов. — М: Триада-Х, 2002. - 116 с.

6. Комаров, И.Г., Комов, Д.В., Гуртовая, И.Б. Диагностическая тактика у больных с метастазами злокачественных опухолей без выявленного первичного очага. — М.: Издательская группа ГУ РОНЦ им. Н.Н. Блохина РАМН, 2005. — 18 c.

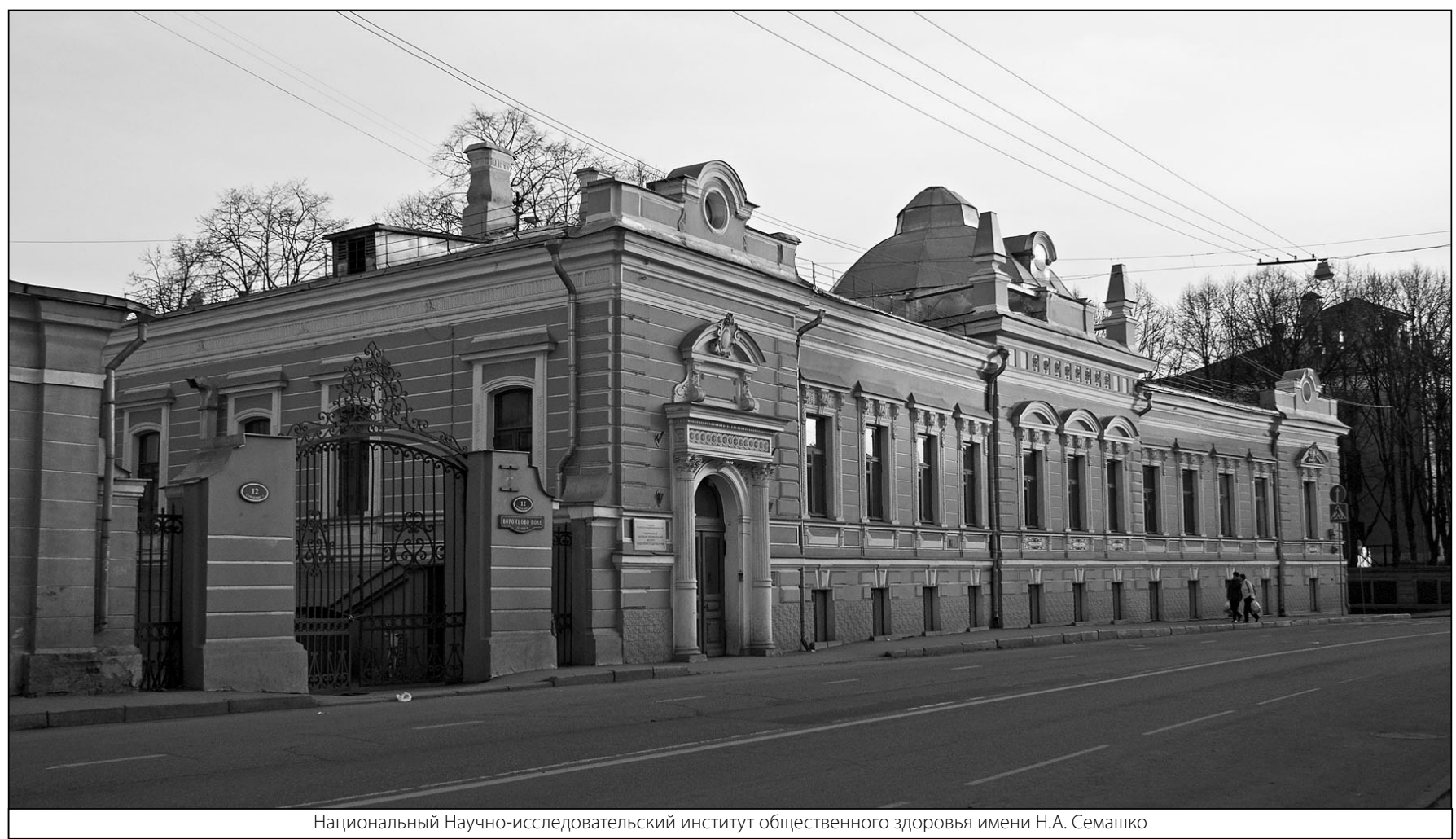

